\title{
Awareness and practice of ergonomics by gynecological laparoscopists in Turkey
}

\author{
Esra Tamburacı®D, Barış Mülayim(1) \\ Antaya Research and Training Hospital, Antalya, Turkey
}

\begin{abstract}
Objectives: Ergonomics in laparoscopy has been gaining increasing attention. The research literature on ergonomics is growing worldwide; however, there are no studies or data from Turkey. Our study provides information on the awareness and use of ergonomics in laparoscopic gynecology in Turkey.

Material and methods: A questionnaire consisting of 25 questions was sent by email to 225 laparoscopists who are members of the Turkish Society of Gynecological Endoscopy.

Results: In response, $45.7 \%$ of the questionnaires were returned. Six respondents (5.9\%) had never experienced pain, and two respondents (1.9\%) always experienced pain during or after laparoscopy. The shoulders, neck, and back were the most common sites where respondents experienced pain. Most of the respondents (64.1\%) utilized one monitor during laparoscopic surgery, and only $2 \%$ of respondents utilized a monitor below eye level. Less than $50 \%$ of the respondents were aware of ergonomic guidelines.

Conclusions: Even though less than half of the Turkish gynecological laparoscopist respondents were aware of ergonomic guidelines, more than half used appropriate visual systems, operating tables, hand instruments, and had large enough operating rooms. Only the number and level of monitors used by respondents were not in accordance with ergonomic guidelines.
\end{abstract}

Key words: ergonomics; laparoscopy; gynecology; Turkey

Ginekologia Polska 2020; 91, 4: 175-180

\section{INTRODUCTION}

Laparoscopic surgery is the standard surgical method in most gynecology departments in Turkey. Laparoscopic surgeries are becoming incorporated into the gynecology residency curriculum in Turkey, as well. As the number of laparoscopic surgeries increases, ergonomics is gaining much more importance. However, is this borne out in practice? Are practitioners aware of ergonomics during laparoscopy [1]?

The advantages of laparoscopic surgery for patients are well known, such as less postoperative pain, shorter recovery time, and better cosmetic results, but the hazards or health risks for laparoscopists, such as musculoskeletal disorders [2,3] or an increased risk of vertebral disc prolapse [4], are not yet well known. Laparoscopy is much more demanding than open surgery owing to visual changes, such as two-dimensional vision and loss of depth perception, as well as a lack of tactile sensation, less freedom of instrument movement, more clutter, and the darkness of the room.
Laparoscopic ergonomics provides appropriate work conditions such as the setup of the operating room and better posture for laparoscopists. Poor posture is the main cause of pain during laparoscopic surgery [5]. Appropriate monitor height and position, table height, port placement, and design of handheld instruments can improve poor posture [6-8]. Correct ergonomics decreases musculoskeletal disorders, suturing time, and complications $[9,10]$. Operating rooms can be inhospitable for laparoscopists if ergonomic rules for laparoscopy are not followed. Much attention is given to the operation itself, but to ensure that a long-lasting, comfortable, pain-free, healthier, and less complicated operation is performed, optimal laparoscopic ergonomics must be provided.

More studies are publishing guidelines concerning ergonomics and musculoskeletal complaints experienced by laparoscopists, which is a positive development, as these issues directly affect laparoscopists. We therefore assessed 
the awareness of ergonomics among Turkish gynecological laparoscopists. To our knowledge, this is the first study from Turkey to investigate laparoscopic ergonomics in gynecology.

\section{MATERIAL AND METHODS}

This study was carried out at Saglık Bilimleri University, Antalya Research and Training Hospital, Antalya, Turkey. The target group for this study included gynecological surgeons who are members of the Turkish Society of Gynecological Endoscopy who perform laparoscopic operations. The Local Ethics Committee of the hospital issued an approval (2018-182) before any study-related procedures were conducted. The participants provided written informed consent before participation.

A questionnaire consisting of 25 questions that could be completed in approximately 5 min was sent by email to 225 laparoscopists between September 1 and September 15, 2018. The subjects received an email with an explanation of the study aims and were asked to fill out the questionnaire on the internet. A total of 103 (45.7\%) surveys were returned during this period. The questionnaire utilized option buttons when only one response could be given and checkboxes when multiple responses could be given. The survey included demographic questions relating to sex, age, body height, dominant hand, years of experience as a laparoscopist, level of laparoscopic surgery, and laparoscopic surgery frequency per week. It also included questions about pain and fatigue during or after laparoscopy, and about monitor number and height, table height, ancillary trocar sites, handheld instrument design, and awareness of ergonomic guidelines. The questionnaire can be found in Table 1 .

\section{RESULTS}

Of the 225 contacted subjects, 103 responded to the questionnaire via the internet, a response rate of $45.7 \%$. However, there were 101 responses to question 9, 102 responses to question 10, 101 responses to question 11,102 responses to question 15,101 responses to question 16,102 responses to question 19, and 100 responses to question 24 .

The characteristics of the respondents are presented in Table 2. Sixty-five (63.1\%) respondents were male, whereas 38 (36.9\%) were female. Most (50.5\%) of the respondents were $31-40$ years of age. Another 39 (37.9\%) respondents were $41-50$ years old, 3 (2.9\%) were younger than 30 years, and $9(8.7 \%)$ were older than 50 years. Most of the respondents were $161-170 \mathrm{~cm}(32 \%)$ or $171-180 \mathrm{~cm}(40.8 \%)$ in height. The vast majority $(100 ; 97.1 \%)$ of the respondents were right-handed.

Regarding laparoscopy experience, 13 (12.6\%) respondents had been performing laparoscopy for more than 15 years, whereas $42(40.8 \%)$ had been performing
Table 1. Questionnaire concerning Laparoscopic Ergonomics in Gynecology

1. What is your gender?

Male

Female

2. What is your height in $\mathrm{cm}$ ?

$150-160$

$161-170$

$171-180$

$>180$

3. What is your dominant hand?

Left

Right

4. Which age range do you belong to?

20-30

$31-40$

$41-50$

$>50$

5. How many years have you been performing laparoscopic surgery? $1-5$

6-10

$11-15$

$>15$

6. Which level do you perform laparoscopy?

Basic (tubal ligation)

Intermediate (ovarian cystectomy, salpingectomy)

Advanced (Total laparoscopic hysterectomy, myomectomy, endometriosis surgery)

7. How many hours a week do you perform laparoscopic surgery?

$1-5$

$5-10$

$10-15$

$>15$

8. Do you feel pain during or after laparoscopy?

Never

Rarely

Sometimes

Often

Always

9. Which part or parts do you feel pain during or after laparoscopy? You can select multiple options.

Neck

Shoulder

Back

Waist

Wrist

Arm

Leg

Foot

None 
Table 1. Questionnaire concerning Laparoscopic Ergonomics in Gynecology (continued)

10. Have you received any treatment for your pain? (medical or physical therapy)

Yes

No

11. Do you feel fatigue during or after laparoscopy?

Yes

No

12. How many monitors do you utilize during laparoscopy?

1

2

3

$>3$

13. What kind of visual system do you have?

Standard

HD

Full HD

Ultra HD (4K)

14. Can you adjust the height of your monitor?

Yes

No

15. At what level do you use your monitor?

Below eye level

At Eye leve

Above eye level

16. Can you adjust the height of the operating table according to your height?

Yes

No

17. At what level do you use the operating table?

Below the waist level

At Waist leve

Above the waist level

18. Are you able to give the desired position to the patient? (stuck arms, enough Trendelenburg position)

Yes

No

19. Is your operating room large enough? (It must be at least 3040 square meters)

Yes

No

20. How do you activate your laparoscopic diathermic or ultrasonic instruments?

By hand

By foot pedal

By both

21. What is your preference for ancillary trocars?

Suprapubic, midline
Table 1. Questionnaire concerning Laparoscopic Ergonomics in

Gynecology (continued)

Ipsilateral

\section{Contralateral}

22. Can you use instruments that fit to your hand size?

Yes

No

23. Which handle type is your laparoscopic forceps?

Axial

Angled ring

Angled shank

24. Which handle type is your laparoscopic needle holder?

Axial

Finger grip

Pistol grip

have no needle holder

25. Are you aware of laparoscopic ergonomic quidelines?

Yes

No

Table 2. The characteristics of the 103 respondents

\begin{tabular}{|c|c|c|}
\hline & & $\mathrm{N}(\%)$ \\
\hline \multirow{2}{*}{ Gender } & Male & 65 (63.1\%) \\
\hline & Female & $38(36.9 \%)$ \\
\hline \multirow{4}{*}{ Age group } & $20-30$ & $3(2.9 \%)$ \\
\hline & $31-40$ & $52(50.5 \%)$ \\
\hline & $41-50$ & $39(37.9 \%)$ \\
\hline & $>50$ & $9(8.7 \%)$ \\
\hline \multirow{4}{*}{ Height of surgeon } & $150-160$ & $9(8.7 \%)$ \\
\hline & $161-170$ & $33(32 \%)$ \\
\hline & $171-180$ & $42(40.8 \%)$ \\
\hline & $>180$ & $19(18.4 \%)$ \\
\hline \multirow{2}{*}{ Dominant hand } & Right & $100(97.1 \%)$ \\
\hline & Left & $3(2.9 \%)$ \\
\hline \multirow{4}{*}{ Number of years in practice } & $1-5$ & $42(40.8 \%)$ \\
\hline & $6-10$ & $31(30.1 \%)$ \\
\hline & $11-15$ & $17(16.5 \%)$ \\
\hline & $>15$ & $13(12.6 \%)$ \\
\hline \multirow{3}{*}{ Laparoscopic surgery level } & Basic & $6(5.8 \%)$ \\
\hline & Intermediate & $28(27.2 \%)$ \\
\hline & Advanced & $69(67 \%)$ \\
\hline \multirow{4}{*}{ Surgery hours a week } & $1-5$ & $62(60.2 \%)$ \\
\hline & $6-10$ & $28(27.2 \%)$ \\
\hline & $11-15$ & $8(7.8 \%)$ \\
\hline & $>15$ & $5(4.9 \%)$ \\
\hline
\end{tabular}

The English in this document has been checked by at least two professional editors, both native speakers of English. For a certificate, please see: http:// www.textcheck.com/certificate/y82Skc 


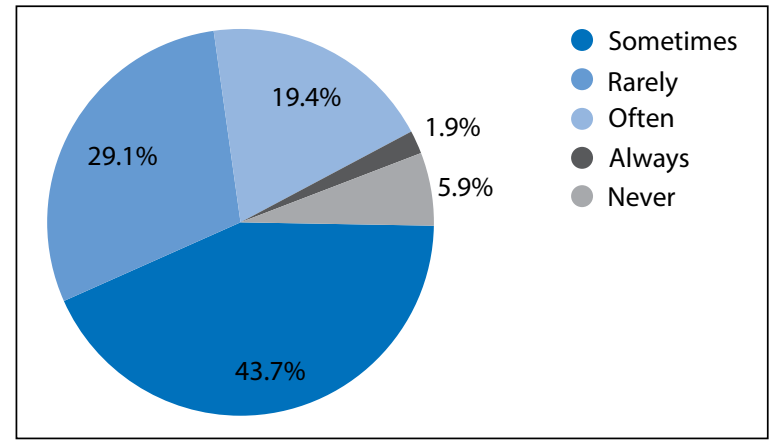

Figure 1. Pain during or after laparoscopy

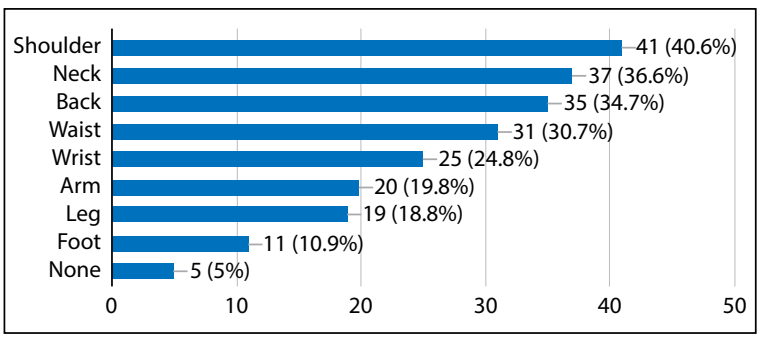

Figure 2. Pain in affected body parts during or after laparoscopy

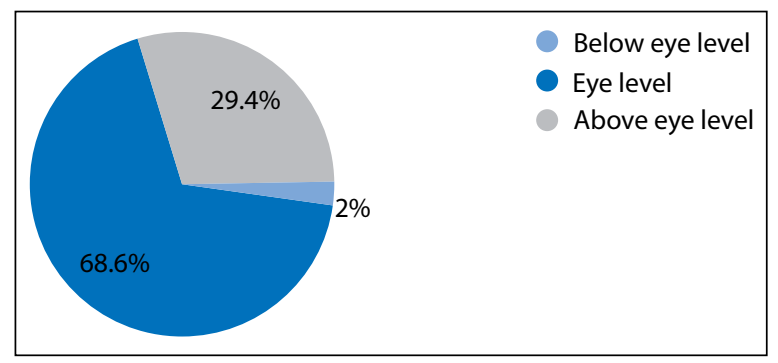

Figure 3. Monitor level preference

laparoscopy for only 1-5 years. A total of 69 (67\%) respondents stated that they could perform advanced laparoscopic surgery such as total laparoscopic hysterectomy, myomectomy, and endometriosis surgery. Sixty-two (60.2\%) respondents reported that they perform laparoscopy $1-5$ hours per week, whereas 28 respondents (27.2\%) perform laparoscopy 6-10 hours per week.

Regarding pain during or after laparoscopy, 6 (5.9\%) respondents reported never experiencing pain, 30 (29.1\%) rarely experienced pain, 45 (43.7\%) sometimes experienced pain, 20 (19.4\%) often experienced pain, and 2 (1.9\%) always experienced pain during or after laparoscopy (Fig. 1).

Figure 2 illustrates that the shoulders, neck, and back were the most common sites where respondents experience pain. Eight respondents declared that they receive physical therapy. Sixty-three (62.4\%) respondents experienced fatigue during or after laparoscopy.

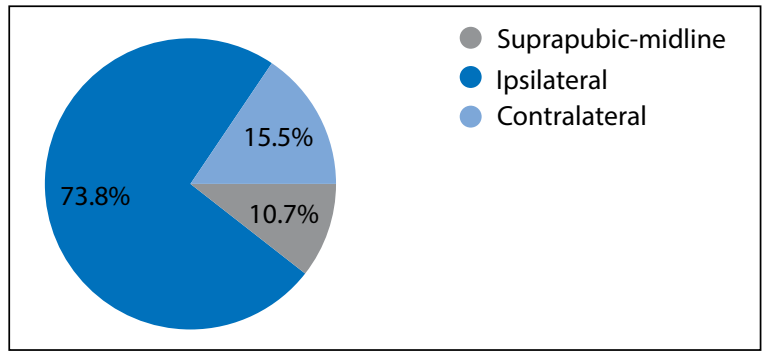

Figure 4. Ancillary trocar site preference

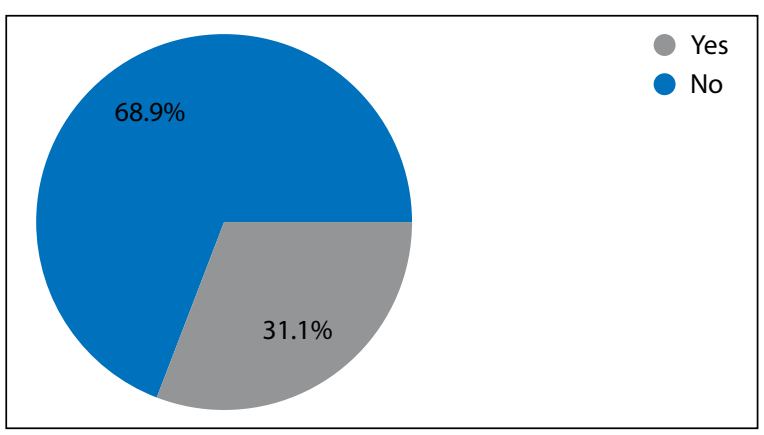

Figure 5. Awareness of laparoscopic ergonomic guidelines

Most (64.1\%) of the respondents utilized one monitor during laparoscopic surgery, and $39.8 \%$ could adjust the monitor height. Most of the respondents had high-definition (HD) (43.7\%) or full HD (30.1\%) visual camera systems. Monitors were utilized above eye level in 30 (29.4\%) respondents, at eye level in 70 (68.6\%), and below eye level in only 2 (2\%) (Fig. 3 ).

Table height was defined as the distance from the tabletop to the floor. When the table was tilted, the tabletop height was measured in terms of the waist height of the laparoscopist when standing. The operating table was utilized mainly at waist level by $56.3 \%$ of the respondents and below waist level by $41.7 \%$. Eight (7.9\%) respondents declared that their operating table was not adjustable. Most (87.4\%) of the respondents reported being able to place patients in the desired position (correct arm position, Trendelenburg angle, etc.). Eighty-four (82.4\%) respondents reported that the operating room was large enough. Seventy-seven (74.8\%) respondents could activate laparoscopic diathermic or ultrasonic instruments via either hand controls or a foot pedal. Seventy-two (69.9\%) respondents reported that they had the opportunity to use instruments that fit their hand size. Angled ring forceps (79.6\%) and axial handle needle holders (64.0\%) were utilized by most of the respondents. Ipsilateral ancillary trocars were generally preferred (73.8\%), as shown in Figure 4. Less than fifty percent of the respondents were aware of ergonomic guidelines as shown in Figure 5. 


\section{DISCUSSION}

Laparoscopy is gaining popularity around the world, including in Turkey. As laparoscopy is being performed more frequently, greater attention and importance are being placed on ergonomics in laparoscopy. Studies on ergonomics are increasing in the medical literature worldwide; however, there are no studies or data from Turkey. Our study provides information on ergonomics of gynecological laparoscopists from Turkey.

Laparoscopy has several advantages for the patient, but is it also beneficial for laparoscopists? Laparoscopy is much more strenuous than open surgery. Continuous isometric muscle contraction, which occurs during laparoscopy and reduces muscle perfusion, resulting in decreased nutrient flow and removal of waste products, which can lead to muscle fatigue and pain. Due to prolonged static postures, laparoscopists experience musculoskeletal discomfort and fatigue of the lower back, neck, and shoulders. Wauben et al. [1] found that of 284 surgeons and residents, nearly $80 \%$ experienced discomfort in the neck, shoulders, and back. The most frequently affected body areas were the shoulders, lower back, and neck (45\%, 26\%, and 15\%), respectively. A total of $72.9 \%$ of respondents were currently suffering or had previously suffered from musculoskeletal complaints in a study by Janki et al. [2]. Respondents most frequently reported experiencing pain in the neck, (lower) back, and shoulders. Franasiak [11] reported that $88 \%$ of laparoscopic gynecological surgeons experienced physical discomfort, particularly neck, shoulder, and back pain, related to minimally invasive surgery. Our results are consistent with the literature with respect to the rates of musculoskeletal complaints and fatigue, and the locations of musculoskeletal complaints.

One of the most important aspects of laparoscopy is the quality of the visual system. Task performance is best when the screen is placed directly in front of the surgeon at an angle of less than $15^{\circ}$ between the viewing direction and working direction, in line with his/her forearm-motor axis. Also, a downward viewing direction of $15^{\circ}$ is suggested as the most neutral viewing direction for the extraocular muscles, or $20 \mathrm{~cm}$ below the height of the surgeon $[12,13]$. The distance between the monitor and the surgeon also impacts eyestrain. Van Det et al. suggested a preferred distance of $80-120 \mathrm{~cm}$ to avoid excessive accommodation, convergence, and staring [14]. The distance of the monitor should be three to nine times greater than the diagonal distance of the monitor screen; however, the minimum distance should be $90 \mathrm{~cm}$, irrespective of monitor size, according to Shallaly and Cuschieri [15].

Although over $75 \%$ of our respondents had HD, full HD, or $4 \mathrm{~K}$ camera systems, more than half had only one monitor, whereas at least two monitors should be used. Moreover, although almost half of respondents are able to adjust the height of their monitors, only $2 \%$ use their monitors below eye level. This suggests that laparoscopic surgeons have not given enough attention to this aspect of ergonomics. This may be the reason the surgeons experience pain during or after the operation, even though most (almost 90\%) respondents reported spending little time (less than $10 \mathrm{~h}$ ) in surgery per week.

Concerning table height, almost all respondents (98\%) used tables below or at waist level. Moreover, $92 \%$ of respondents could adjust the table height according to their body height and thus have suitable tables for laparoscopic operations. The potential issue with this is if the surgeon and co-surgeon are of different heights, but this can be solved using a step or platform.

Task difficulties are lowest when the handles of the instruments are positioned at, or $5 \mathrm{~cm}$ above, the elbow height of the surgeon; in other words, the angle range at the elbow should be $90-120^{\circ}$. To maintain instruments at elbow height, the ergonomic operating surface height should be $70-80 \%$ of the surgeon's ground-to-elbow distance, usually $65-100 \mathrm{~cm}$. The optimal table height is influenced by the elbow angle, instrument handle design, extracorporeal instrument shaft length, and port location. Proper trocar placement is an essential step in the laparoscopic approach for optimal vision of the operative field and enhanced recognition of structures and pathologic conditions. Correct trocar placement can minimize instrument and scope interference (the "dueling swords" phenomenon), optimize ergonomics, decrease mental and muscular fatigue, cut down on lost time and effort, and thereby markedly increase safety and ensure good surgical practice. There is no uniform consensus on port placement, and it is necessary to understand triangulation and optimal angles to better understand port placement. Trocars are usually placed in triangular fashion; the target organ should be 15-20 cm from the center port used for the optical trocar, and the remaining trocars are placed in a $15-20 \mathrm{~cm}$ arc at $5-7 \mathrm{~cm}$ on either side of the optical trocar [16]. The best ergonomic layout for endoscopic surgery consists of a manipulation angle ranging from $45^{\circ}$ to $75^{\circ}$, with equal azimuth angles [17]. In our survey, most of the respondents utilized ancillary trocars ipsilaterally; this is likely because the suturing courses of the Turkish Society of Gynecological Endoscopy utilize ipsilateral ancillary trocars rather than suprapubic or contralateral ones.

Appropriate patient positioning is very important during laparoscopic surgery; in particular, the arms should be tucked in, the buttocks should be near the table edge, and the patient should be in the $15-30^{\circ}$ Trendelenburg position while operating. Nearly $90 \%$ of our respondents had no 
problem with appropriate patient positioning, which is very good. In our clinic, the modified lithotomy position, called the Lloyd Davies position, is used.

There is no consensus on the design of handheld instruments, but we know that one size or design does not fit all. Interestingly, more than $50 \%$ of our respondents had the opportunity to use whatever handheld instruments they desired and those that fit their hand size, which is very uncommon among laparoscopists around the world.

In general terms, a laparoscopist must squeeze harder, bend the wrists more, and hold his/her arms higher when using laparoscopic instruments compared with open instruments. Together, these factors can produce substantial hand and shoulder fatigue and discomfort during laparoscopic surgery. The instrument handle should be designed according to the task performed: pistol-type handles for tasks that require force and precision-type handles for tasks that require precision.

Limitations of the study are the sample is not representative of the entire Turkish gynecological laparoscopists community and it is not based on objective data due to it is a survey study.

In conclusion, although less than half of the Turkish gynecological laparoscopists who responded to our survey were aware of ergonomic guidelines, more than half of them had appropriate visual systems, operating tables, and handheld instruments and large enough operating rooms.

In our study, although there was less pain and loss of labor compared to other studies, the lack of awareness about ergonomics was similar. In order to reduce the risks of injuries for both surgeons and surgeons-in-training, medical sectors should attach more importance to ergonomics. Although many sectors other than the medical industry place emphasis on ergonomics, most surgeons still lack ergonomic training [18].

\section{Acknowledgments}

We would like to thank all members of Turkish Society of Gynecological Endoscopy (TSGE) members participating in this study and our sincere gratitude to Prof Fatih Sendag MD. president of TSGE.

\section{Conflict of interest}

Dr. Esra Tamburaci, and Dr.Baris Mulayim have no conflicts of interest or financial ties to disclose.

\section{REFERENCES}

1. Wauben LS, van Veelen MA, Gossot D, et al. Application of ergonomic guidelines during minimally invasive surgery: a questionnaire survey of 284 surgeons. Surg Endosc. 2006; 20(8): 1268-1274, doi: 10.1007/s00464005-0647-y, indexed in Pubmed: 16858528.

2. Janki S, Mulder EE, IJzermans JNM, et al. Ergonomics in the operating room. Surg Endosc. 2017; 31(6): 2457-2466, doi: 10.1007/s00464-0165247-5, indexed in Pubmed: 27752811.

3. van Veelen MA, Nederlof EAL, Goossens RHM, et al. Ergonomic problems encountered by the medical team related to products used for minimally invasive surgery. Surg Endosc. 2003; 17(7): 1077-1081, doi: 10.1007/s00464-002-9105-2, indexed in Pubmed: 12728378.

4. Cass GKS, Vyas S, Akande V. Prolonged laparoscopic surgery is associated with an increased risk of vertebral disc prolapse. J Obstet Gynaecol. 2014; 34(1): 74-78, doi: 10.3109/01443615.2013.831048, indexed in Pubmed: 24359056

5. Alleblas CCJ, de Man AM, van den Haak L, et al. Prevalence of Musculoskeletal Disorders Among Surgeons Performing Minimally Invasive Surgery: A Systematic Review. Ann Surg. 2017; 266(6): 905-920, doi: 10.1097/SLA.0000000000002223, indexed in Pubmed: 28306646.

6. Szeto GPY, Cheng SWK, Poon JTC, et al. Surgeons' static posture and movement repetitions in open and laparoscopic surgery. J Surg Res. 2012; 172(1): e19-e31, doi: 10.1016/j.jss.2011.08.004, indexed in Pubmed: 22079837.

7. Supe AN, Kulkarni GV, Supe PA. Ergonomics in laparoscopic surgery. J Minim Access Surg. 2010; 6(2): 31-36, doi: 10.4103/0972-9941.65161, indexed in Pubmed: 20814508.

8. Yeola M, Gode D, Bora A. Ergonomics in Laparoscopy. Int J Recent Surg Med Sci. 2019; 03(02): 102-108, doi: 10.5005/jp-journals-10053-0051.

9. Quinn D, Moohan J. Optimal laparoscopic ergonomics in gynaecology. The Obstetrician \& Gynaecologist. 2015; 17(2): 77-82, doi: 10.1111/tog.12176.

10. Hemal AK, Srinivas M, Charles AR. Ergonomic problems associated with laparoscopy. J Endourol. 2001; 15(5): 499-503, doi: 10.1089/089277901750299294, indexed in Pubmed: 11465329.

11. Franasiak J, Ko EM, Kidd J, et al. Physical strain and urgent need for ergonomic training among gynecologic oncologists who perform minimally invasive surgery. Gynecol Oncol. 2012; 126(3): 437-442, doi: 10.1016/j. ygyno.2012.05.016, indexed in Pubmed: 22613351.

12. Current state of ergonomics of operating rooms of Dutch hospitals in the endoscopic era. Minim Invasive Ther Allied Technol. 2004; 13(3): 156-160, doi: 10.1080/13645700410034093, indexed in Pubmed: 16754504.

13. Veelen MA, Jakimowicz JJ, Goossens RHM, et al. Evaluation of the usability of two types of image display systems, during laparoscopy. Surg Endosc. 2002; 16(4): 674-678, doi: 10.1007/s00464-001-9116-4, indexed in Pubmed: 11972213.

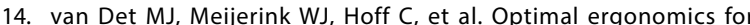
laparoscopic surgery in minimally invasive surgery suites: a review and guidelines. Surg Endosc. 2009; 23(6): 1279-1285, doi: 10.1007/s00464008-0148-x, indexed in Pubmed: 18830751.

15. El Shallaly G, Cuschieri A. Optimum view distance for laparoscopic surgery. Surg Endosc. 2006; 20(12): 1879-1882, doi: 10.1007/s00464005-0162-1, indexed in Pubmed: 17031749.

16. Ferzli GS, Fingerhut A. Trocar placement for laparoscopic abdomina procedures: a simple standardized method. J Am Coll Surg. 2004; 198(1): 163-173, doi: 10.1016/j.jamcollsurg.2003.08.010, indexed in Pubmed: 14698326.

17. Manasnayakorn S, Cuschieri A, Hanna GB. Ideal manipulation angle and instrument length in hand-assisted laparoscopic surgery. Surg Endosc. 2008; 22(4): 924-929, doi: 10.1007/s00464-007-9520-5, indexed in Pubmed: 17704859.

18. Catanzarite T, Tan-Kim J, Whitcomb EL, et al. Ergonomics in Surgery: A Review. Female Pelvic Med Reconstr Surg. 2018; 24(1): 1-12, doi: 10.1097/SPV.0000000000000456, indexed in Pubmed: 28914699. 